\title{
REVISÃO BIBLIOGRÁFICA: A PRÓPOLIS COMO ADITIVO NA NUTRIÇÃO DE FRANGOS DE CORTE
}

\author{
Literature review: propolis as an additive in broilers' nutrition
}

\begin{abstract}
Carla Patricia Freitas ${ }^{1 *}$; Daniela Cechin²; Lára Franco Santos ${ }^{3}$; Nadálin Yandra Botton ${ }^{4}$; Ana Caroline Tissiani ${ }^{3}$; Luciana Ruschel dos Santos ${ }^{3}$; Mauro Antônio de Almeida ${ }^{2}$; Rogério Luis Cansian $^{2}$; Daniela dos Santos de Oliveira ${ }^{2}$
\end{abstract}

\footnotetext{
$1 *$ Universidade Regional Integrada do Alto Uruguai e das Missões, URI Erechim e Universidade de Passo Fundo - UPF, E-mail: 182113@upf.br

${ }^{2}$ Universidade Regional Integrada do Alto Uruguai e das Missões, URI - Erechim, RS

${ }^{3}$ Universidade de Passo Fundo, UPF - Passo Fundo, RS

${ }^{4}$ Universidade Federal de Pelotas, UFPEL - Pelotas, RS
}

Data do recebimento: 26/02/2021 - Data do aceite: 12/07/2021

\begin{abstract}
RESUMO: A restrição do uso de antibióticos como melhoradores de desempenho na avicultura de corte, levou as indústrias de nutrição animal a direcionar suas pesquisas por substâncias que possam ser alternativas a esses aditivos. A própolis, substância resinosa e balsâmica coletada pelas abelhas a partir de plantas, tem sido foco de estudos como aditivo natural nas rações de frangos de corte, visando a melhorar os índices zootécnicos, devido as suas propriedades, com ação sobre o sistema imune e metabolismo das aves. No entanto, existem divergências nos resultados encontrados na literatura, e mais estudos devem ser realizados referentes à dose-resposta, esclarecendo os benefícios da própolis na nutrição avícola. Assim, o objetivo dessa revisão foi abordar o efeito da própolis como melhorador de desempenho nas dietas de frangos de corte.
\end{abstract}

Palavras-chave: Avicultura. Extrato natural. Melhorador de desempenho.

ABSTRACT: The restriction of antibiotics use as performance enhancers in poultry farming has led animal nutrition industries to direct their research 
towards substances that can be alternatives to these additives. Propolis, a resinous and balsamic substance collected by bees from plants, has been the focus of studies as a natural additive in chicken feed, improving zootechnical indexes, due to its properties acting on the metabolism and immune system of the birds. However, there are divergences in the results found in the literature, and further studies should be carried out regarding dose-response, clarifying the benefits of propolis in poultry nutrition. Thus, the aim of this review was to address the effect of propolis as a performance enhancer in broilers' diets.

Keywords: Poultry. Natural extract. Performance enhancer.

\section{Introdução}

A cadeia produtiva de frangos de corte brasileira tem destaque no setor do agronegócio, devido aos avanços tecnológicos na genética, nutrição, rastreabilidade e biosseguridade, que resultam em um constante crescimento da produção (ESPINDOLA, 2012). Em 2019, o Brasil foi o maior exportador mundial de carne de frango com um volume total de 4,214 milhões de toneladas, enquanto a produção superou os 13,245 milhões de toneladas, assumindo a terceira posição, atrás dos Estados Unidos e da China. Do total de frangos produzidos, $68 \%$ foram destinados ao mercado interno e $32 \%$ para exportação (ABPA, 2020).

Aliado ao melhoramento genético, a nutrição contribuiu para o sistema de criação de frangos de corte, produzindo carne em menor tempo, além de melhorar o desempenho relacionado diretamente com a conversão alimentar, peso médio do frango e redução de idade de abate (SANTINI, 2006). O uso de antimicrobianos em frangos de corte foi utilizado com função terapêutica ou melhorador de desempenho, atuando diretamente sobre a microbiota intestinal e melhorando os índices zootécnicos.

No entanto, com a resistência microbiana e a necessidade em atender as exigências do consumidor, que ampliou seu padrão alimentar nos últimos anos e tem optado por produtos naturais, saudáveis e seguros, existe uma tendência em abolir os antimicrobianos utilizados como melhoradores de desempenho (SCHMIDT; SILVA, 2018). Com isso, as indústrias da área de nutrição animal tem direcionado suas pesquisas no desenvolvimento de produtos alternativos eficientes no desempenho de animais de produção, com a redução de patógenos e da imunomodulação do trato gastrointestinal e sem resíduos na carne que possam comprometer a saúde do consumidor (KURITZA et al., 2014).

A indústria avícola tem utilizado enzimas, extratos de plantas, óleos essenciais, ácidos orgânicos, probióticos, prebióticos e os produtos apícolas também ganham espaço em pesquisas como melhoradores de desempenho alternativos, que surgem como uma fonte alimentar alternativa e promissora na nutrição animal (GENOVA et al., 2020).

A própolis é uma combinação de material resinoso e balsâmico, coletada pelas abelhas e unidas com secreções salivares e outras substâncias. Pesquisas com a própolis vem ganhando espaço no campo científico devido às suas propriedades biológicas antibacterianos, anti-inflamatórios, antifúngicos, imunomoduladoras, antioxidantes e antivirais; à sua composição rica em compostos fenólicos, podendo ser utilizada na indústria alimentícia, em substituição aos aditivos sin- 
téticos (VASILAKI et al., 2019) e, também, na alimentação animal, com a finalidade de melhorar a saúde e prevenir doenças (MAHMOUD et al., 2015).

Esta revisão bibliográfica, apresenta os resultados de produções científicas que utilizaram a própolis como aditivo natural e melhorador de desempenho indicando benefícios deste produto na nutrição de frangos de corte.

\section{Material e Métodos}

Realizou-se uma revisão bibliográfica com os artigos científicos indexados nas bases de dados Pubmed-NCBI (https://www. ncbi.nlm.nih.gov/pubmed/), Scielo - Scientific Eletronic Library Online (https://search. scielo.org/), Researchgate (http://www. researchgate.net) e ScienceDirect (https:// www.sciencedirect.com). Foram utilizadas as combinações entre as palavras-chave própolis, extratos etanólicos de própolis, nutrição de frangos de corte, própolis na nutrição de animais de produção, melhoradores de desempenho, aditivos e promotores de crescimento. Os critérios de inclusão dos estudos foram artigos em português e inglês, com publicações veiculadas entre 2010 até 2020, com discussão do uso da própolis como melhorador de desempenho e efeito sobre os índices zootécnicos na nutrição de frangos de corte. Foram excluídos artigos que associavam a própolis como aditivo para outras finalidades.

\section{Desenvolvimento}

\section{Produção e Composição Química da Própolis}

A própolis é uma substância natural, composta por resinas e compostos balsâmicos coletada pelas abelhas a partir de plantas (brotos, ramos e flores), combinada por secreções salivares e enzimas, sendo os principais constituintes $50 \%$ de resinas de plantas, $30 \%$ de ceras, $10 \%$ de óleos essenciais e $5 \%$ de grão de pólen, além de alguns minerais $(\mathrm{Mn}$, $\mathrm{Cu}, \mathrm{Ca}, \mathrm{Al}, \mathrm{Na}, \mathrm{Fe}, \mathrm{Zn}$ e $\mathrm{Mg}, \mathrm{K}$ ) e vitaminas (A, B1, B2, B6, C e E) (VASILAKI et al., 2019).

As abelhas utilizam a própolis na construção de seus ninhos, como forma de vedamento da colmeia para impedir a entrada de vento e de predadores, além de manter a saúde da colônia e do mel, devido à sua atividade antimicrobiana (CAMPOS et al., 2015). Assim, tem sido foco de investigações científicas com o intuito de melhorar os parâmetros zootécnicos, pois além de possuir os nutrientes básicos tem atividades biológicas, na sua composição, com ação sobre diversos microrganismos (LACERDA et al., 2011; EYNG et al., 2016; SILVA et al., 2016). No entanto, sua composição química pode variar conforme a origem geográfica, botânica, o gênero e a espécie de abelha, o que resulta em diferentes atividades biológicas.

A própolis tem aproximadamente 300 compostos, sendo os polifenóis principal grupo, são formados por ácidos fenólicos e flavonoides com propriedades biológicas como ação antimicrobiana (PRZYBYLEK; KARPIŃSKI, 2019), antioxidante, anti-inflamatória, imunomoduladora, cicatrizante, anestésica, antiviral (SCHNITZLER et al., 2010) e antiprotozoário (GRESSLER et al., 2012; FREITAS et al., 2016). No entanto, isso não significa que amostras de própolis com maior quantidade desses compostos terão maior atividade biológica, uma vez que sua ação depende da concentração das substâncias, forma de aplicação, quantidade de composto disponível, dentre outras particularidades (VALERO, 2010).

A produção dos extratos de própolis é uma etapa fundamental para a obtenção de um 
produto final de qualidade, com a finalidade de extrair maior quantidade de compostos bioativos presentes sem alterar suas propriedades química e física. Portanto, para atingir uma extração eficiente desses compostos, depende da temperatura, solvente, tempo de extração e tamanho de partícula utilizada (MELLO et al., 2010). Para a identificação e quantificação dos compostos químicos, diversos métodos são utilizados, como cromatografia em camada delgada (CCD), cromatografia gasosa (CG), cromatografia líquida (CL), espectrometria de massas e a cromatografia líquida de alta eficiência (HPLC) a mais utilizada.

A própolis tem sido explorada na área da alimentação animal de ruminantes, na produção, composição e na capacidade antioxidante de vacas leiteiras (AGUIAR et al., 2014), e de não-ruminantes na dieta de frangos de corte (MAHMOUD et al., 2015). A própolis modifica o perfil de bactérias presentes no aparelho gastrointestinal, confirmado em algumas pesquisas que avaliaram a utilização desses extratos naturais sobre a seleção de bactérias e sobre o desempenho animal em ruminantes e não-ruminantes (PRADO, 2010).

Para frangos de corte, a própolis tem sido utilizada na ração tanto na forma bruta como no extrato etanólico de própolis (EEP), promovendo melhoria da saúde intestinal, controlando a multiplicação de microrganismos patógenos e, consequentemente, melhorando as funções digestivas e a absorção de nutrientes, sem resíduos na carne e sem prejuízos à saúde do consumidor (EYNG et al., 2013).

\section{Própolis como melhorador de desempenho}

O uso de aditivos naturais nas dietas de frangos de corte, com ação antimicrobiana, tem a função de prevenir doenças e melhorar o desempenho, promovendo o equilíbrio da microbiota intestinal, evitando lesões no sistema digestório provocadas por patógenos que, consequentemente, reduzem a digestibilidade e absorção dos nutrientes e o desempenho dos animais (GERON et al., 2013).

Eyng et al. (2013) utilizaram a própolis nas dietas de frangos de corte de 1 a 21 dias de idade, nas concentrações de 0 a 5000 ppm e obtiveram resultados positivos na saúde e na morfometria intestinal com a adição de 3000 ppm. No entanto, os autores constataram que a suplementação com 1000 a 5000 ppm na fase pré-inicial, prejudicou o desempenho das aves, sendo semelhantes entre os grupos experimentais, recuperando o desempenho a partir de 21 dias de idade. Outros estudos comparando a própolis com níveis de inclusão na dieta de frangos de corte a $0,20 \mathrm{~g} / \mathrm{kg}$ e com um probiótico comercial (PrimaLac ${ }^{\circledR}$ ) a $0,45 \mathrm{~g} / \mathrm{kg}$, isolados ou em combinação com a própolis, não foram promissores em relação ao desempenho dos frangos, reduzindo o peso corporal aos 21 e 42 dias de idade quando comparada aos outros tratamentos, em contraste com o estudo anterior que teve aumento no desempenho aos 21 dias. Já a combinação própolis e probiótico mostrou efeito positivo na conversão alimentar e como imunomodulador sobre os frangos de corte do que frangos alimentados somente com probiótico nas primeiras 3 semanas (DANESHMAND et al., 2015).

Os extratos de própolis nas concentrações de $50,100,200$ e $300 \mathrm{mg} / \mathrm{kg}$ e o antibiótico flavofosfolipol $(4,5 \mathrm{mg} / \mathrm{kg}$ ) adicionados na dieta de frangos de corte não afetaram significativamente os critérios de desempenho durante todo o experimento (1 a 42 dias de idade), mas os tratamentos tenderam a aumentar o peso corporal e a ingestão diária em comparação com o grupo controle. A dieta suplementada com $200 \mathrm{mg} / \mathrm{kg}$ de EEP obtiveram melhores resultados de ganho em comparação a outros grupos (GHEISARI et al., 2017). 
Já Torki et al. (2015) utilizaram óleo essencial de cominho $(0,8 \mathrm{~g} / \mathrm{kg})$ e extrato etanólico de própolis $(0,2 \mathrm{~g} / \mathrm{kg})$ nas dietas de frangos de corte de 1 a 42 dias de idade e observaram o oposto em seus resultados, quando os EEP foram adicionados às dietas dos frangos, melhorou durante todo o período experimental o peso corporal, ganho de peso corporal, consumo de ração e conversão alimentar, sendo que o óleo essencial de cominho também proporcionou melhor desempenho, mas os EEP não apresentaram nenhum efeito significativo nas características da carcaça, em concordância com Eyng et al. (2013).

Outro estudo foi realizado utilizando EEP $(0,1000,2000,3000,4000$ e $5000 \mathrm{ppm})$ e resíduo de própolis (RP) em concentrações de $0,100,200,300,400$ e $500 \mathrm{ppm}$, sobre o desempenho e a microbiota intestinal de frangos de corte em dois ensaios e observaram que o EEP não afetou significativamente $o$ desempenho e a microbiota intestinal, porém o RP modulou a microbiota cecal sem nenhum efeito sobre o desempenho (EYNG et al., 2016). Assim, os níveis de inclusão de RP e EEP podem ser usados em dietas de frangos de corte, sem causar nenhum efeito adverso sobre desempenho de 1 a 21 dias de idade, observado também por Duarte et al. (2014).

Outros relatos citam os efeitos positivos de extratos vegetais e/ou própolis no ganho de peso corporal (AAMI-AZGHADI et al., 2010). A suplementação de dietas com vitamina C (500 ppm) e chumbo (200 ppm), e outra, própolis $(1 \mathrm{~g} / \mathrm{kg}$ ) e chumbo (200 ppm) foram adicionadas nas dietas de frangos de 1 a 42 dias de idade submetidos ao estresse oxidativo pela administração de chumbo, mostraram que a vitamina $\mathrm{C}$ e a própolis melhorou o ganho de peso corporal, conversão alimentar e rendimento de carcaça da coxa e peito (SEVEN et al., 2012).

Outros dois experimentos foram conduzidos em um mesmo estudo, visando a avaliar os efeitos da suplementação com própolis na densidade de alojamento (aves $/ \mathrm{m}^{2}$ ), no desempenho de crescimento, digestibilidade ideal de nutrientes, morfologia intestinal e resposta imunológica de frangos de corte de 1 a 42 dias de idade, submetidos ao estresse térmico. No Experimento I as aves foram suplementadas com dietas contendo própolis a $1,2,3,4$ e $5 \mathrm{~g} / \mathrm{kg}$ de ração. Os resultados mostraram maior ganho médio diário de peso e consumo médio diário de ração em níveis de inclusão de $4 \mathrm{~g} / \mathrm{kg}$ e aumento da altura das vilosidades e da profundidade das criptas no jejuno com 4 a $5 \mathrm{~g} / \mathrm{kg}$ de própolis do que os tratados com a dieta sem aditivos. No Experimento II foram utilizados dois níveis de própolis ( 0 ou $4 \mathrm{~g} / \mathrm{kg}$ de dieta) e dois níveis de densidade de alojamento, baixa (10 aves/ $\mathrm{m}^{2}$ ) ou média $\left(14 \mathrm{aves} / \mathrm{m}^{2}\right)$. A própolis teve efeito positivo no sistema imunológico e nos indicadores de estresse de frangos de corte, alojados em densidade média (CHEGINI et al., 2019). Estudos mostraram desempenho das aves prejudicado somente sob condições de estresse agudo (ABUDABOS et al., 2013; CENGIZ et al., 2015).

Diante disso, a suplementação de dietas com própolis pode ser usada como melhorador de desempenho, proporcionando melhor crescimento em frangos criados sob altas temperaturas ambientais e diferentes densidades (HOSSEINI et al., 2016). Esse efeito benéfico está associado aos compostos bioativos da própolis, como flavonoides totais e ácido benzóico que podem aumentar o metabolismo das aves, melhorando a absorção dos nutrientes e a imunidade (ATTIA et al., 2014; HANHINEVA et al., 2010).

Os flavonoides possuem uma hidroxila (aglicona ou genina) em sua composição, semelhante ao estrogênio, que pode promover atividade hormonal de crescimento (ZIARAN et al., 2005). Quando os flavonoides e fenóis são ingeridos pela ave, na dieta, esses compostos são absorvidos no 
intestino delgado praticamente inalterados (WALLE, 2004), ainda, metabolizados por algumas bactérias (Lactobacillus e Bifidobacterium), produzindo outros metabólitos que podem ser utilizados por células bacterianas como fonte de energia, promovendo efeito de crescimento (LEE et al., 2006). Também exercem atividade antioxidante em nível celular e tecidual e além da atividade antimicrobiana, favorecem a multiplicação de bactérias benéficas, mantendo o controle das bactérias patogênicas evitando danos à mucosa intestinal das aves e consequentemente melhores medidas morfométricas das vilosidades duodenais e criptas, aumentando a absorção dos nutrientes contidos na ração (PRAKATUR et al., 2019).

A redução do ganho de peso corporal e consumo de ração na fase pré-inicial, com inclusão de própolis, conforme mostraram alguns estudos citados, diminuiu o desempenho dos frangos à medida que se aumentava $\mathrm{a}$ concentração de própolis. Assim, testes com dosagens inferiores devem ser analisadas visando a concentrações que não prejudiquem os parâmetros de desempenho na fase pré-inicial, ou seja, dosagens com melhor desempenho em cada fase de produção.

Outro fator importante quando se avalia o desempenho de frangos de corte são as interferências do ambiente, o grau de estresse térmico (que pode levar a menor consumo de ração e ganho de peso), com possibilidade de afetar negativamente o desempenho da ave. Outro fator importante seriam as diferentes densidades de alojamento, que provocam mudanças no comportamento das aves e, consequentemente, a diminuição da eficiência energética (CENGIZ et al., 2015). Segundo Houshmand et al. (2012), quanto mais energia para adaptação às condições de estresse, menos energia será utilizada para o crescimento. Assim, a eficiência das dietas com inclusão de própolis pode estar relacionada, não apenas à dose utilizada, mas também às condições do estudo como estresse calórico e superlotação.

Os estudos sobre os efeitos dos suplementos com EEP sobre a alimentação das aves ainda não estão claros, possivelmente devido à complexidade da molécula própolis, que apresenta composição química variável, conforme a área geográfica e botânica, além da ausência de padronização dos métodos para a extração dos compostos bioativos, tipos de solventes, temperatura e tempo de extração, que podem resultar em diferentes concentrações de compostos presentes na própolis (PRADO, 2005).

Essa diversidade dificulta a comparação dos resultados apresentados por diferentes autores. Também, a dose utilizada, o ambiente e as condições nas quais os animais foram tratados bem como o metabolismo de cada animal podem influenciar os resultados em relação aos índices zootécnicos.

\section{Considerações Finais}

A partir desta revisão foi possível identificar os benefícios que a própolis promove, tanto no sistema imune quanto no metabolismo dos frangos de corte, melhorando os índices zootécnicos e informando o setor de nutrição sobre seu uso como uma alternativa de aditivo natural nas dietas de frangos de corte.

A dificuldade em padronizar a própolis não impede sua utilização como aditivo natural na nutrição de frangos de corte. Conforme comprovado nos estudos, a própolis proporcionou benefícios quando foi suplementada nas dietas, melhorando o sistema imune, mantendo a saúde intestinal, o controle de microrganismos patógenos, aumentando a absorção dos nutrientes contidos na ração e, consequentemente, contribuindo com o desempenho das aves. No entanto, uma investigação mais aprofundada da dose-resposta é necessária para evitar o desperdício dessa 
matéria-prima produzida em pequena escala pelas abelhas, assim, tornando um aditivo natural viável, economicamente, e sem pro- vocar perdas no desempenho das aves nas diferentes fases de crescimento.

\section{REFERÊNCIAS}

AAMI-AZGHADI M.; GOLIAN A.; KERMANSHAHI H.; SEDGHI M. Comparison of dietary supplementation with cumin essential oil and prebiotic fermacto on humoral immune response, blood metabolites and performance of broiler chickens. Global Veterinária, v. 4, n. 4, p. 380-387, 2010. Disponível em: https://www.researchgate.net/publication/267702118_Comparison_of_Dietary_ Supplementation_with_Cumin_Essential_Oil_and_Prebiotic_Fermacto_on_Humoral_Immune Response_Blood_Metabolites_and_Performance_of_Broiler_Chickens. Acesso em: 10 mar. 2021. ABPA. Annual Report of the Brazilian Association of Animal Protein. 2020. Disponível em: https:// abpa-br.org/wpcontent/uploads/2020/05/abpa_relatorio_anual_2020. Acesso em: 10 mar. 2021.

ABUDABOS A. M.; SAMARA, E. M.; HUSSEIN, E. O. S.; AL-GHADI, M. Q.; ALATIYAT, R. M. Impacts of stocking density on the performance and welfare of broiler chickens. Italian Journal Animal Sciences, v. 12, n. 11, p. 66-71, 2013. Disponível em: https://www.researchgate. net/publication/235929495_Impacts_of_stocking_density_on_the_performance_and_welfare_of_ broiler_chickens. Acesso em: 15 jan. 2021.

AGUIAR, S. C.; COTTICA, S. M.; BOEING, J. S.; SAMENSARI, R. B.; SANTOS, G. T.; VISENTAINER, J. V.; ZEOULA, L. M. Effect of feeding phenolic compounds from propolis extracts to dairy cows on milk production, milk fatty acid composition, and the antioxidant capacity of milk. Animal Feed Science and Technology, v. 193, p. 148-154, 2014. Disponível em: https:// www.sciencedirect.com/science/article/abs/pii/S0377840114001266. Acesso em: 13 jan. 2021.

ATTIA, Y. A.; ABD AL-HAMID, A. E.; IBRAHIM, M. S.; AL-HARTHI, M. A.; BOVERA, F.; EL-NAGGAR, A. Productive performance, biochemical and hematological traits of broiler chickens supplemented with propolis, bee pollen, and mannan oligosaccharides continuously or intermittently. Livestock Science. v. 164, p. 87-95, 2014. Disponível em: https://www.sciencedirect.com/science/ article/abs/pii/S1871141314001358. Acesso em: 11 jan. 2021.

CAMPOS, J. F.; DOS SANTOS, U. P.; DA ROCHA, P.; DAMIÃO, M. J.; BALESTIERI, J. B.; CARDOSO, C. A.; PAREDES-GAMERO, E. J.; ESTEVINHO, L. M.; DE PICOLI SOUZA, K.; DOS SANTOS, E. L. Antimicrobial, Antioxidant, Anti-Inflammatory, and Cytotoxic Activities of Propolis from the Stingless Bee Tetragonisca fiebrigi (Jataí). Evidence-Based Complementary and Alternative Medicine, v. 2015, p. 1-11, 2015. Disponível em: https://www.ncbi.nlm.nih.gov/pmc/ articles/PMC4491730/. Acesso em: 14 jan. 2021.

CENGIZ, Ö; KÖKSAL, B. H.; TATLI, O.; SEVIM Ö.; AHSAN, U.; ÜNER, A. G.; ULUTAS, P. A.; BEYAZ, D.; BÜYÜKYÖRÜK, S.; YAKAN, A. Effect of dietary probiotic and high stocking density on the performance, carcass yield, gut microflora, and stress indicators of broilers. Poultry Sciences, v. 94, p. 2395-2403, 2015. Disponível em: https://pubmed.ncbi.nlm.nih.gov/26240393/. Acesso em: 17 mar. 2021.

CHEGINI, S.; KIANI, A.; KAVAN, B. P.; ROKNI, H. Effects of propolis and stocking density on growth performance, nutrient digestibility, and immune system of heat-stressed broilers. Italian Journal of Animal Science, v. 18, n. 1, p. 868-876, 2019. Disponível em: https://www.tandfonline. com/doi/full/10.1080/1828051X.2018.1483750. Acesso em: 12 fev. 2021. 
DANESHMAND, A.; SADEGHI, G.H.; KARIMI, A.; VAZIRY, A.; IBRAHIM, A. S. 'Evaluating complementary effects of ethanol extract of propolis with the probiotic on growth performance, immune response and serum metabolites in male broiler chickens', Livestock Science, v. 178, p. 195-201, 2015. Disponível em: https://www.sciencedirect.com/science/article/abs/pii/ S1871141315001936. Acesso em: 10 fev. 2021.

DUARTE, C. R. A.; EYNG, C.; MURAKAMI, A. E.; SANTOS, T. C. Intestinal morphology and activity of digestive enzymes in broilers fed crude propolis. Canadian Journal of Animal Science, v. 94, p. 105-114, 2014. Disponível em: https://www.researchgate.net/publication/277676812 Intestinal_morphology_and_activity_of_digestive_enzymes_in_broilers_fed_crude_propolis. Acesso em: 12 jan. 2021.

ESPINDOLA, J. C. Trajetórias do progresso técnico na cadeia produtiva de carne de frango do Brasil. Geosul, v. 27, n. 53, p. 89, 2012. Disponível em: https://www.researchgate.net/ publication/286663253_Trajetorias_do_progresso_tecnico_na_cadeia_produtiva_de_carne_de_ frango_do_Brasil. Acesso em: 09 mar. 2021.

EYNG C.; MURAKAMI A. E.; PEDROSO, A. A.; DUARTE, C. R. A.; PICOLI, K. P. Caecal microbiota of chickens fed diets containing propolis. Journal of Animal Physiology Animal Nutrition, v. 101, n. 3, p. 484-492, 2016. Disponível em: https://onlinelibrary.wiley.com/doi/ epdf/10.1111/jpn.12570. Acesso em: 5 fev. 2021.

EYNG, C.; MURAKAMI, A.E.; DUARTE, C.R.A.; SANTOS, T.C. Effect of dietary supplementation with an ethanolic extract of propolis on broiler intestinal morphology and digestive enzyme activity. Journal of Animal Physiology and Animal Nutrition, v. 98. p. 393-401, 2013. Disponível em: https://pubmed.ncbi.nlm.nih.gov/23909488/. Acesso em: 20 fev. 2021.

FREITAS, C. P.; MANICA, E.; DEBORTOLI, B. P.; OLIVEIRA, V. E.; SANTOS, J. PAIVA, F. A. Avaliação in vitro da Própolis de Abelhas Jataí como Anticoccidiano em Frangos de Corte. In: XXVI CONGRESSO BRASILEIRO DE ZOOTECNIA, ZOOTEC, 2016. Cinquenta Anos de Zootecnia no Brasil. 2016, Santa Maria/RS. Anais [...]. Santa Maria: Associação Brasileira de Zootecnistas, p. 11-13, , 2016.

GENOVA, J. L.; RODRIGUES, R. B.; MARTINS, J. S.; UCZAY, M.; HENRIQUES, J. K. S. Própolis e pólen apícola na nutrição de animais não ruminantes. Archivos de zootecnia, v. 69, n. 265, p. 124-131, 2020. Disponível em: https://www.uco.es/ucopress/az/index.php/az/article/ view/5048. Acesso em: 10 fev. 2021.

GERON, L. J.V.; SILVA, G. P.; MACHADO, T. R. J; SILVA, D. A.; SOUZA, O. M. Utilização de própolis (aditivo promotor de crescimento natural) na nutrição de ruminantes. PUBVET, Londrina, v. 7, n. 13, ed. 236, art. 1557, 2013. Disponível em: http://www.pubvet.com.br/artigo/654/ utilizaccedilatildeo-de-proacutepolis-aditivo-promotor-de-crescimento-natural-na-nutriccedilatildeode-ruminantes. Acesso em: 19 fev. 2021.

GHEISARI, A.; SHAHRVAND, S.; LANDY, N. Effect of ethanolic extract of propolis as an alternative to antibiotics as a growth promoter on broiler performance, serum biochemistry and immune responses, Veterinary World, v. 10 n. 2, p. 249-254, 2017. Disponível em: https://www. ncbi.nlm.nih.gov/pmc/articles/PMC5352853/. Acesso em: 01 mar. 2021.

GRESSLER, L. T.; SILVA, A.; MACHADO, G.; ROSA, L.; DORNELES, F.; GRESSLER, L.; OLIVEIRA, M.; ZANETTE, R.; VARGAS, A.; MONTEIRO, S. Susceptibility of Trypanosoma evansi to propolis extract in vitro and in experimentally infected rats. Research in Veterinary Science, v. 93, n. 3, p. 1314-1317, 2012. Disponível em: https://pubmed.ncbi.nlm.nih. gov/22405907/. Acesso em: 5 mar. 2021.

HANHINEVA, K.; TÖRRÖNEN, R.; BONDIAPONS, I.; PEKKINEN, J.; KOLEHMAINEN, M.; MYKKÄNEN, H.; POUTANEN, K. Impact of dietary polyphenols on carbohydrate metabolism. 
International Journal of Molecular Sciences, v. 11, p. 1365-1402, 2010. Disponível em: https:// pubmed.ncbi.nlm.nih.gov/20480025/. Acesso em: 12 fev. 2021.

HOSSEINI, S. M.; VAKILI AZGHANDI, M.; AHANI, S.; NOURMOHAMMADI, R. Effect of bee pollen and propolis (bee glue) on growth performance and biomarkers of heat stress in broiler chickens reared under high ambient temperature. Journal of Animal and Feed Sciences, v. 25, p. 45-51, 2016. Disponível em: https://www.researchgate.net/publication/303787373_Effect_of_ bee_pollen_and_propolis_bee_glue_on_growth_performance_and_biomarkers_of_heat_stress_in broiler_chickens_reared_under_high_ambient_temperature. Acesso em: 5 jan. 2021.

HOUSHMAND, M.; AZHAR, K.; ZULKIFLI, I.; BEJO, M. H.; KAMYAB, A. Effects of prebiotic, protein level, and stocking density on performance, immunity, and stress indicators of broilers. Poultry Science. v. 91, p. 393-401, 2012. Disponível em: https://pubmed.ncbi.nlm.nih. gov/22252353/. Acesso em: 10 jan. 2021.

KURITZA, L. N.; WESTPHAL, P.; SANTIN, E. Probióticos na avicultura. Ciência Rural, Santa Maria, v. 44, n. 8, p. 1457-1465, 2014. Disponível em: https://www.scielo.br/pdf/cr/v44n8/01038478-cr-44-08-01457.pdf. Acesso em: 19 fev. 2021.

LACERDA, R. C. C.; TIVERON, A. P.; ALENCAR, S. M. Própolis e Segurança Alimentar Propolis , Food Safety and Security. Segurança alimentar e nutricional, v. 18, n. 2, p. 99-106, 2011. Disponível em: https://www.researchgate.net/publication/323021640_Propolis_e_Seguranca_ Alimentar. Acesso em: 22 fev. 2021.

LEE, H. C.; JENNER, A. M.; LOW, C. S.; LEE, Y. K. Effect of tea phenolics and their aromatic fecal bacterial metabolites on intestinal microbiota. Research in Microbiology , v. 157, p. 876-884, 2006. Disponível em: https://pubmed.ncbi.nlm.nih.gov/16962743/. Acesso em: 15 fev. 2021.

MAHMOUD, U. T.; ABDEL-RAHMAN, M. A.; DARWISH, M. H. A.; APPLEGATE, T. J.; CHENG, H. W. Behavioral changes and feathering score in heat stressed broiler chickens fed diets containing different levels of propolis. Applied Animal Behaviour Science, v. 166, p. 98-105, 2015. Disponível em: https://www.sciencedirect.com/science/article/abs/pii/S0168159115000891. Acesso em: 11 jan. 2021.

MELlO, B. C. B. S; PETRUS, J. C. C.; HUBINGER, M. D. Desempenho do processo de concentração de extratos de própolis por nanofiltração. Ciência e Tecnologia de Alimentos, Campinas, v. 30, n. 1, p. 166-172, 2010. Disponível em: https://www.scielo.br/pdf/cta/v30n1/ v30n1a25.pdf. Acesso em: 7 mar. 2021.

PRADO, O. P. P. Produto à base de própolis na nutrição de ruminantes (LLOS). 2005. 107 p. Dissertação (Mestrado em Produção Animal), Universidade Estadual de Maringá, Maringá, PR, 2005. Disponível em: https://periodicos.ufba.br/index.php/rbspa/article/view/40350/22461. Acesso em: 14 mar. 2021.

PRADO. O. P. P.; ZEOULA, L. M.; PONTARA, L. P. De M.; FRANCO, S. L.; NOVELLO, C. R.; GERON, L. J. V. Adição de própolis ou monesina sódica sobre digestibilidade in vitro da matéria seca em dietas 50:50\% volumoso:concentrado e 100\% volumoso. Revista Brasileira de Saúde e Produção Animal, v. 11, n. 4, p. 1023, 2010. Disponível em: https://periodicos.ufba.br/index.php/ rbspa/article/view/40350/22461. Acesso em: 14 mar. 2021.

PRAKATUR, I.; MISKULIN, M.; PAVIC, M.; MARJANOVIC, K.; BLAZICEVIC, V.; MISKULIN, I.; DOMACINOVIC, M. Intestinal Morphology in Broiler Chickens Supplemented with Propolis and Bee Pollen. Multidisciplinary Digital Publishing Institute - MDPI, v. 9, p. 12, 2019. Disponível em: https://www.ncbi.nlm.nih.gov/pmc/articles/PMC6617278/. Acesso em: 15 fev. 2021.

PRZYBYLEK, I.; KARPIŃSKI, T. M. Antibacterial properties of propolis. Molecules, v. 24, n. 11, p. 11-13, 2019. Disponível em: https://pubmed.ncbi.nlm.nih.gov/31146392/. Acesso em 11 fev. 2021. 
SANTINI, G. A. Dinâmica Tecnológica da cadeia de frango de corte no Brasil: Análise dos segmentos de insumos e processamento. 2006. 269 f. Tese (Doutorado em Engenharia de Produção) Universidade Federal de São Carlos, São Carlos, SP, 2006. Disponível em: https://repositorio.ufscar. $\mathrm{br} /$ handle/ufscar/3474?show=full ed=y. Acesso em: 9 fev. 2021.

SCHMIDT, N. S.; SILVA, C. L. DA. Pesquisa E Desenvolvimento na Cadeia Produtiva de Frangos de Corte no Brasil. Revista de Economia e Sociologia Rural, v. 56, n. 3, p. 467-482, 2018. Disponível em: https://www.scielo.br/scielo.php?script=sci_arttext\&pid $=$ S0103-20032018000300467. Acesso em: 5 mar. 2021.

SCHNITZLER, P.; NEUNER, A.; NOLKEMPER, S.; ZUNDEL, H.; SENSCH, K.; REICHLING, J. Antiviral Activity and Mode of Action of Propolis Extracts and Selected Compounds.

Phytotherapy Research, v. 24, p. 20-28, 2010. Disponível em: https://www.researchgate.net/ publication/26243811_Antiviral_Activity_and_Mode_of_Action_of_Propolis_Extracts_and_ Selected_Compounds. Acesso em: 20 abr. 2021.

SEVEN, I.; AKSU, T.; TATLI SEVEN, P.The effects of propolis and vitamin c supplemented feed on performance, nutrient utilization and carcass characteristics in broilers exposed to lead. Livestock Science v. 148, p. 10-15, 2012. Disponível em: https://agris.fao.org/agris-search/search. do?recordID=US201400055704. Acesso em: 7 jan. 2021.

SILVA, R. P. D.; MACHADO, B. A. S.; COSTA, S. S.; BARRETO, G. A.; PADILHA, F. F.; UMSZA-GUEZ, M. A. Application of propolis extract in food products: A prospecting based in patent documents. Revista Virtual de Quimica, v. 8, n. 5, p. 1251-1261, 2016. Disponível em: http://static.sites.sbq.org.br/rvq.sbq.org.br/pdf/v8n5a02.pdf. Acesso em: 6 fev. 2021.

TORKI, M.; SOLTANI, J.; MOHAMMADI, H. Effects of adding ethanol extract of propolis and cumin essential oil to diet on the performance, blood parameters, immune response and carcass traits of broiler chicks. Iranian Journal of Applied Animal Science, v. 5 n. 4, p. 911-918, 2015. Disponível em: http://ijas.iaurasht.ac.ir/e_516543_4e3e3dff8654340353af77353fa21857.pdf. Acesso em: 23 jan. 2021.

\section{VALERO, M. V. Monensina ou própolis na dieta de bovinos mestiços terminados em}

confinamento: desempenho, digestibilidade, produção microbiana, características de carcaça e do músculo longissimus, 2010. p.77. Dissertação (Mestrado em Zootecnia), Área de Concentração de Produção Animal, Universidade Estadual de Maringá, Maringá, 2010. Disponível em: http://www. pcs.uem.br/ppz/trabalhos-de-conclusao/dissertacoes/2010/maribel-velandia-valero. Acesso em: 11 jan. 2021.

VASILAKI, A.; HATZIKAMARI, M.; STAGKOS-GEORGIADIS, A.; GOULA, A. M.; MOURTZINOS, I. A natural approach in food preservation: Propolis extract as sorbate alternative in non-carbonated beverage. Food Chemistry, v. 298, p. 125080, 2019. Disponível em: https://www. sciencedirect.com/science/article/abs/pii/S0308814619311847. Acesso em: 22 jan. 2021.

WALLE, T. Absorption and metabolism of flavonoids. Free Radical Biology \& Medicine, v. 36, p. 829-837, 2004. Disponível em: https://www.sciencedirect.com/science/article/abs/pii/ S0891584904000346. Acesso em: 5 jan. 2021.

ZIARAN, H. R.; RAHMANI, H. R.; POURREZA, J. Effect of dietary oil extract of propolis on immune response and broiler performance. Pakistan Journal of Biological Sciences, v. 8, p. 1485-1490, 2005. Disponível em: https://www.researchgate.net/profile/Hamidreza-Rahmani/ publication/26565174_Effect_of_Dietary_Oil_Extract_of_Propolis_on_Immune_Response_and Broiler_Performance//inks/00 $\bar{b} 4951 \mathrm{cdbe} 810 \mathrm{~d} 4 \mathrm{fd} 000000 /$ Effect-of-Dietary-Oil-Extract-of-Propolison-Immune-Response-and-Broiler-Performance.pdf. Acesso em: 12 mar. 2021. 